\title{
Soil flushing by surfactant solution: pilot-scale tests of complete technology
}

\author{
M. Šváb ${ }^{1}$, M. Kubal ${ }^{2} \&$ M. Kuraš $\check{s}^{2}$ \\ ${ }^{I}$ Dekonta, a.s., Ustí nad Labem, Czech Republic \\ ${ }^{2}$ Institute of Chemical Technology Prague, Czech Republic
}

\begin{abstract}
This paper relates to PCBs contaminated soil flushing process, in which the aqueous solution of anionic surfactant Spolapon AOS 146 was passed through the sandy soil having an average PCBs concentration of $34.3 \mathrm{mg} / \mathrm{kg}$ of dry matter.

The laboratory part was focused in particular on the selection of a suitable surfactant for PCBs solubilisation from the soil and to the development of the soil extract processing technique which took place before the realisation of the pilot-scale demonstration of the soil flushing technology.

The experimental pilot-scale facility used consisted of a steel column $(3 \mathrm{~m}$ length, $1.5 \mathrm{~m}$ diameter) containing $1.7 \mathrm{~m}^{3}$ of polluted soil and a liquid circulation system, by which an aqueous solution of the surfactant was supplied to the soil. Spolapon solution $(40 \mathrm{~g} / \mathrm{l})$ was passing through the soil column for 2.5 months. The concentration of surfactant and PCBs in the final aqueous extract was monitored during this time period. The final PCBs concentration profile in the soil was determined after stopping the liquid flow. After passing through the soil the PCBs containing aqueous extract was pumped out from the steel column bottom to a treatment unit, where it was processed by the adsorptive micellar flocculation followed by carbon black adsorption. The degree of PCBs removal from aqueous extract to coagulation sludge of $99.99 \%$ was observed. In terms of the mass balance all PCBs removed from the soil were concentrated in $14 \mathrm{~kg}$ of sludge with moisture content of $66 \%$. A decrease in PCBs concentration to $15 \mathrm{mg} / \mathrm{kg}$ of dry soil was achieved, but it is certain that a decrease to level of units $\mathrm{mg} / \mathrm{kg}$ could be achieved in the case of a longer duration of flushing.

Keywords: soil, PCBs, surfactant, flushing.
\end{abstract}




\section{Introduction}

Proposals for remediation of soils polluted by polychlorinated biphenyl (PCB) compounds have included incineration, solidification/vitrification, and electrokinetic approaches. However, mainly because of costs, environmental constrains and efficacy many of these approaches have never been applied in the field-scale system. That is why other more efficient methods for treating PCBs contaminated soils continue to be proposed, optimized and evaluated [1].

Numerous advanced remediation technologies have been developed recently for the clean up of soils polluted by PCBs. Significant attention is devoted to the process in which the PCBs are leached out from the soil by using surfactants solutions. This technique is mostly called soil flushing when used as in-situ process or soil washing for ex-situ batch arrangement $[2,3,4]$.

The positive effect of surfactant presence in aqueous phase in contact with PCBs contaminated soil to PCBs solubility has been known for many years [5]. Treatment technique based on surfactant solution flushing/washing has been found to be able to reduce hydrophobic hydrocarbons content in solid contaminated materials [6]. Especially, leaching with surfactant can effectively and cheaply substitute very expensive thermal methods (the only methods able to reduce the PCBs and other persistent species from soils), at least for lesscontaminated soils.

\section{Background}

Many papers describing background of surfactant effect on NAPL (non aqueous phase liquid) aqueous solubilisation from soil have been published [7]. Main important property of the surfactants discussed in many studies is a critical micelle concentration (CMC). Above this concentration the surfactants become to be efficient for solubilisation of non-polar species in aqueous solution. This solubilisation takes place inside of the micelles formed. Due to the wide range of variable parameters (available surfactants, type of the soil and contaminant, contaminant-soil bond type etc), it is difficult to provide some general methodology for suitable surfactant selection in case of particular soil and contaminant. Usually, only some general principles are suggested for surfactant selection [8]. For the NAPL contaminants solubilisation from soils, only surfactants of anionic and non-ionic type are mostly considered [7]. Cationic surfactants are not suitable because of their high sorption onto mostly negatively charged sorption surfaces in the soils. Finally, each project focused on application of the surfactant solution leaching of NAPL contaminants from soil should consist of the laboratory research (in which the suitable surfactant is selected based on some experiments) followed by the pilot-scale demonstration of the technology to verify the laboratory-obtained data.

The project presented deals both with the laboratory part and with the pilotscale demonstration of the soil flushing. The laboratory part containing also suggestion of the simple mathematical model of the studied process has been presented on ConSoil conference 2005 [9]. This study was focused mainly to the 
results of the laboratory research (suitable surfactant selection, determination of the CMC value, suggestion of the mathematical model) and their comparison with the model calculations of flushing in the pilot-scale demonstration.

The study presented here describes complete pilot-scale demonstration including processing of soil leachate, mass balance and evaluation of the technology.

\section{Pilot-scale demonstration description}

The aim of the pilot-scale demonstration was to verify efficacy, time-demands and technology aspects, which are not available in laboratory scale. Experiment was designed based on knowledge of results of preliminary laboratory part, in which Spolapon AOS 146 was selected as suitable anionic surfactant for solubilisation of PCBs from soil to the aqueous solution. Its CMC was estimated as $1.34 \mathrm{~g} / \mathrm{L}$ [9]. Methods for processing of soil extract have been also tested in laboratory part involving flocculation, absorption into organic solvent and adsorption by carbon black. The best method proved to be flocculation. The soil used for pilot-scale demonstration was sampled on the same site (and same place) in Czech Republic like the soil for the laboratory experiments.

\subsection{Chemicals, solvents and surfactants}

Sample of anionic surfactant with trade name Spolapon AOS 146 was provided by Enaspol Velvety Co. (Czech Republic). The product contains 38 weight $\%$ of active surfactant component. Structure of the surfactant is based on linear sodium alkane-sulfonates (C14-C16).

\subsection{Analytical methods used}

The PCBs content in the soil was analyzed in the following way: known mass of the soil sample between 0.8 and $1.5 \mathrm{~g}$ (precisely measured on the analytical balances) was extracted for 4 hours by hexane at the temperature of its boiling point (Soil was placed between the boiling test-tube and back flow condenser of hexane, in this way, the soil extraction by the fresh solvent had been achieved.). The soil extract in the boiling test-tube containing whole PCBs content of the soil was then passed through a column with length of $10 \mathrm{~cm}$ and diameter of 3 $\mathrm{mm}$ filled with an activated Florisil. The extract was filled up to the volume of $10 \mathrm{ml}$ by the hexane and PCBs concentration was measured on the gas chromatograph with the ECD detector. Only six congeners (number 28, 52, 101, $153,138,180)$ of the PCBs were quantitatively determined in accordance with the Czech legislation. PCBs content in the sample represent sum of those six congeners concentrations.

The PCBs concentration in the liquid aqueous samples was determined after extraction with $10 \mathrm{ml}$ of hexane for 2 hours with shaking, separation of the hexane phase sample and purification of it by use of the same column of Florisil as in the case of the soil samples extracts.

Analysis of anionic surfactant content in the liquid aqueous samples was done by the volumetric method in two-phase system chloroform-water. Methylene 
blue solution was used as indicator while solution of cationic substance Septonex was a volumetric agent. At the beginning of the titration in the presence of anionic surfactant blue color remains in the chloroform phase. As titration (in term of addition of the volumetric solution) continues, blue color passes into the water phase. Point of equivalence was determined as decolorizing of the chloroform phase.

\subsection{Experimental facility}

Technological arrangement shown schematically in the Figure 1 was constructed for purpose of the soil flushing demonstration. Most important part of the technology was the flushing tank with diameter of $1.46 \mathrm{~m}$ and height of $3 \mathrm{~m}$ which has been equipped with the filtration bed on the bottom part. It consisted of a layer of the gravel covered by layer of sand and geotextile. The flushing tank was placed in the retaining tank for collection of soil leachate equipped by pump. The pump was able to pump the soil leachate either to the tank for waste water (not displayed in the Figure 1) or to the tank for collection of soil extract. Bottom of the retaining tank was equipped with valve enabling to discharge tank completely and then to measure flushing solution flow through the flushing tank (in assumption that flow through valve and flushing tank should be equivalent). In the upper part of the flushing tank was installed an electrode system connected with control unit and pump of fresh flushing solution installed near the tank with flushing solution. This system was able to control layer of flushing solution in the flushing tank on constant level.

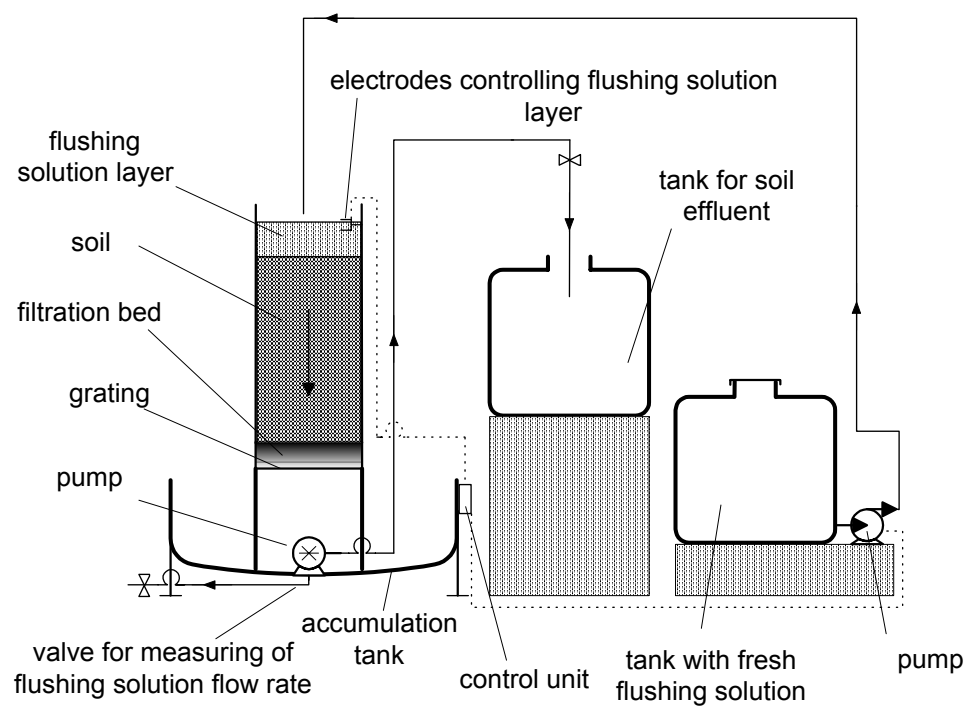

Figure 1: $\quad$ Pilot-scale demonstration facility scheme. 


\subsection{Process description}

Soil used was sandy soil with organic carbon content of $1.45 \%$, bulk density of $1.63 \mathrm{~g} / \mathrm{cm} 3$ and estimated effective porosity of $40 \%$. At the beginning of the pilot-scale demonstration, about 1.7 cubic meter of the soil was mixed with water to form a dense suspension, which was then introduced into the flushing column by use of the barrels and forklift. After settling down the soil formed $1 \mathrm{~m}$ high layer in the column. Rest of the water set-off from the soil was removed from the flushing tank by the pipe (by use of the effect of layers levels difference). Samples of the initial soil were taken from the homogenized suspension before introducing it to the flushing column to know an input PCBs concentration. Initial PCBs concentration founded was about $34 \mathrm{mg} / \mathrm{kg}$ of dry soil.

Flushing solution concentration of anionic surfactant Spolapon AOS 146 was $40 \mathrm{~g} / \mathrm{L}$. Relatively high concentration was chosen due to the results of laboratory experiments and with respect to expected duration of the pilot-scale demonstration needed to reach some demonstrable changes in the PCBs concentrations in soil. The flushing solution was pumped up to the soil in the flushing column to make a layer of $30 \mathrm{~cm}$. It was kept constant during the flushing process by electrodes connected with control unit. In fact, by operation, the flushing pilot-scale demonstration was started.

During the process, one or twice per week, flow of flushing solution through the soil layer was measured after pumping out the soil leachate from retaining tank either to the tank for waste water or to the tank for processing of it. Content of the retaining tank was pumped to the wastewater tank during the beginning phase of the soil flushing. Soil sorption capacity was not yet saturated and because of it, concentrations of both the surfactant and PCBs were very low. Moment, in which it was needed to pump leachate into the tank for processing was observed only visually - from leachate color and foam, what gives evidence that concentrations of both the surfactant and PCBs became to increase. When the retaining tank was empty, valve in its bottom was opened for at least 1 hour to get the same flow through valve and flushing column. After that, flushing solution was measured by use of volumetric cylinder. The soil leachate collected in the cylinder was then taken as sample. In this way, the flushing process was simulated for approximately 2 months.

Flushing process was terminated by removal of the flushing solution layer from the top of the flushing tank. After the predominant part of the flushing solution drained out from the soil layer, the final sampling of the flushed soil has been carried out. To this purpose, three holes were made into the soil layer in the flushing tank by use of the equipment, which allows cutting the sample of the whole soil profile. Three sampled profiles were divided into 8 sections and then, mixed sample has been prepared from the same sections of each profile. In these 8 samples, final residual PCBs concentration was determined.

Soil leachate in the tank for processing of it was processed by patented method based on coagulation [10]. Dose of ferric trichloride was $0.017 \mathrm{~mol} / \mathrm{L}$. After addition of this agent and neutralisation by addition of calcium hydroxide to reach suspension of $\mathrm{pH} 7$, period of fast mixing (about $600 \mathrm{rpm}$ ) for 5 minutes 
was followed by period of slow mixing (about $150 \mathrm{rpm}$ ) for approx. 10 minutes. Simple stirrer (usually used for stirring of paints) powered by handy electric drill was used for mixing of the suspension. After sedimentation for 2 days, filtrate was separated from the sludge by filtration through textile bags, type PM10MY (Czech producer). Before filtration, it was possible to directly remove approx. $70-80 \%$ of liquid above the settled sludge.

\section{Results}

First important information provided by pilot-scale demonstration was flushing solution flow rate through the soil layer during the demonstration period. This flow rate was expected to be decreasing with time according to the theoretical assumption. Flow rate in beginning phase of the flushing was $2 \mathrm{~L} /$ hour and it decreased to $0.6 \mathrm{~L} /$ hour during the period of 2 months. It was possible to interpolate the flow rate lowering by powered function. Further flow rate decreasing seemed to be slow, so we could expect the limiting constant flow rate in case of longer flushing should range between $0.5-0.55 \mathrm{~L} /$ hour. This flow rate should be constant for potential further long duration of flushing.

Figure 2 shows both the PCBs and the surfactant concentration in the soil leachate during the flushing. There is evident relation between concentration of the surfactant and of the PCBs in the solution. It is clear, that presence of the surfactant directly determines higher concentration of the PCBs in the solution in comparison with the pure water. It is expectable, that concentration of the PCBs would rise above to the final value measured in the pilot-scale demonstration. It is evident from this fact, that decontamination is faster and more efficient (for example in term of flushing solution consumption needed to remove unit of PCBs from soil) with process time because of the increasing of the PCBs concentration in leachate. It remains to comment why the concentrations became to rise before one pore volume of the flushing solution flowed through the soil, especially when sorption of the surfactant onto soil particles has been expected from laboratory experiments (approx. $8 \mathrm{~g} / \mathrm{Kg}$ ). Probably, it was caused by combination of two facts. In first, Figure 2 was constructed for estimated soil porosity of $40 \%$, but even little change in the porosity estimate strongly affects the pore volumes in which the concentrations became to rise. We can also expect that the flow of solution through the soil in the pilot-scale experiment was not piston-flow, e.g. some preference pathways could occurred in the soil layer. Those two effects probably predominates the sorption, from which we expected increase of both (PCBs and surfactant) concentration later. Finally, it was positive observation, that $\mathrm{PCBs}$ became to be removed from the soil sooner than it could be expected from surfactant sorption behavior.

The Figure 3 shows final PCBs concentration profile after the flushing was terminated. It is obvious from the profile that PCBs were concentrated in the bottom part of the soil layer, what has been caused by the surfactant adsorption onto soil in the top part of the layer during the beginning phase of the flushing. Concentration of PCBs in the top part of the layer was probably affected by gravitation separation of the soil particles in the column that occurred during 
introducing the soil suspension into the column. Finest particles, which are usually most contaminated due to their larger sorption surface, remained on the top of the layer. It was the reason why the residual PCBs concentration in the soil (top part of the column) seemed to be unexpectedly high (about $15 \mathrm{mg} / \mathrm{kg}$ ). This observation was confirmed by sieving analysis of the soil used. There is a relevant reason to await the residual PCBs soil concentration lower than the observed value at the top part of the column. It can be expected that in case of sufficiently long flushing, concentration in whole profile of the soil should decrease on level equal to the top part of the soil layer. In this way, decontamination efficacy observed was about $56 \%$, but it can be expected that efficiency could be substantially higher $(>90 \%)$. Time needed to reach this efficiency in whole profile can be estimated between 6-12 months (estimated simply from mass balance of PCBs).

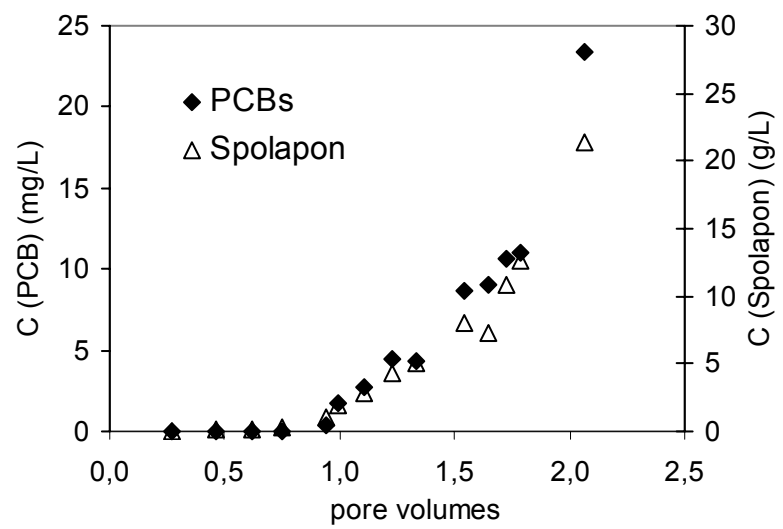

Figure 2: Concentration of both PCBs and surfactant in soil leachate during pilot-scale demonstration of soil flushing.

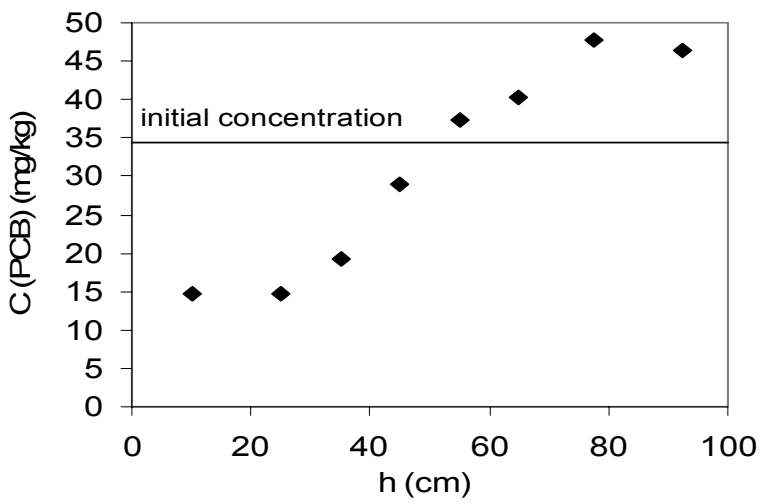

Figure 3: Residual PCBs concentration profile in the soil layer after the pilotscale flushing was terminated. 
Mass balance of the flushing showed the recovery value of the PCBs of $98.8 \%$ what was significantly better than it could be expected before. This high recovery was surprisingly better than it has been expected. Total volume of the soil leachate was 1.4 cubic meters. Of this volume, about $500 \mathrm{~L}$ was directly pumped to the tank for wastewater during the beginning phase of the experiment (see Figure 2), because both concentrations were very low. Rest of soil leachate, $900 \mathrm{~L}$, was collected in the plastic tank with volume of 1 cubic meter. Concentrations of PCBs and of Surfactant in the soil leachate (solution in tank) were $8.1 \mathrm{mg} / \mathrm{L}$ and $8 \mathrm{~g} / \mathrm{L}$, respectively. The soil leachate was processed by above described patented coagulation method. Complete information about the processing of soil leachate are summarised in Table 1.

Table 1: $\quad$ Summarisation of soil leachate processing.

\begin{tabular}{|l|l|}
\hline volume of leachate processed & $\sim 900 \mathrm{~L}$ \\
\hline initial concentration of PCBs & $8.1 \mathrm{mg} / \mathrm{L}$ \\
\hline initial concentration of surfactant & $8 \mathrm{~g} / \mathrm{L}$ \\
\hline residual PCBs concentration in filtrate & $24 \mathrm{ng} / \mathrm{L}$ \\
\hline residual surfactant concentration in filtrate & $2.2 \mathrm{~g} / \mathrm{L}$ \\
\hline mass of produced sludge & $14.2 \mathrm{~kg}$ \\
\hline moisture of sludge & $66 \%$ \\
\hline concentration of PCBs in sludge & $1145 \mathrm{mg} / \mathrm{kg}$ (dry sludge) \\
\hline
\end{tabular}

It is obvious from Table 1, that PCBs were removed from the soil leachate into the sludge with very high efficiency exceeding $99.99 \%$. It remains to refer about the analytical complication caused by presence of phthalates in the filtrate (from plastic tank). Therefore, it was necessary to eliminate this disturbing effect by modified analytical process in specialised analytical laboratory. From Table 1 also results that PCBs removed from 2.7 tons of soil were concentrated into $14 \mathrm{~kg}$ of the sludge. The sludge was then burned in the incinerator (in Ostrava, Czech Republic).

\section{Conclusions}

The pilot-scale demonstration study confirmed that it is possible to remove the PCBs from the real contaminated soil by the flushing with surfactant solution. Decontamination efficiency proved was $56 \%$, but it could be higher than $90 \%$ in case of longer duration of the flushing process. Time needed to reach this efficiency can be estimated as 6-12 months. Water consumption can be estimated to be approximately 2-3 cubic meters of water per 1 cubic meter of soil. However, it should be possible to recycle water in the process because the residual PCBs concentration in processed soil leachate was very low $(24 \mathrm{ng} / \mathrm{L})$. So, total fresh water consumption should be relatively low due to its recirculation. Costs of decontamination of 1 cubic meter of soil can be estimated between 200-250 Euro/t (including wastes utilisation, costs of investments are not included). In principle, it could be possible to operate the technology both 
in-situ and ex-situ. We can expect, that ex-situ method should be more efficient, faster and safer towards surrounding environment, but more cost demanding (due to investments). Decision about the technological design of flushing process has to be done with respect to the particular conditions - soil permeability, hydraulic conditions on locality, local legislation etc.

Technology of soil flushing by surfactant aqueous solution could be serious competition to expensive thermal methods especially for less-contaminated soils (up to approximately hundreds $\mathrm{mg} / \mathrm{kg}$ ).

\section{References}

[1] Wu O., Marshall W.D.: Approaches to the Remediation of Polychlorinated Biphenyl (PCB) Contaminated Soil - a Laboratory Study, Journal of Environmental Monitoring, 3 (2001), 281-287.

[2] Otten A., Alphenaar A., Pijls CH., Spuij F., Wit H.: In Situ Soil Remediation, Kluwer Academic Publishers, Dordrecht 1997.

[3] Roote D. S.: In Situ Flushing, GWRTAC Technology Overview Report, TO-97-02, 1997.

[4] Mann J.M.: Full-scale and pilot-scale soil washing, Journal of Hazardous Materials 66 (1999), 119-136.

[5] Haigh S.D.: A Review of the Interaction of Surfactants With Organic Contaminants in Soil, The Science of the Total Environment 185 (1996), 161-170.

[6] Mulligan C.N., Yong R.N., Gibbs B.F.: Surfactant-enhanced Remediation of Contaminated Soil: a Review, Engineering Geology 60 (2001), 371380.

[7] Haigh S.D.: A review of the interaction of surfactants with organic contaminants in soil, The Science of the Total Environment 185 (1996), 161-170.

[8] Jafvert Ch.T.: Sufactants/Cosolvents, Technology Evaluation Report TE96-02, 1996 Purdue University.

[9] Svab M., Raschman R., Kubal M.: PCBs Removal from Contaminated Soil by means of Surfactants: Pilot-scale Tests, ConSoil 2005, 3.-7. 10.2005, Bordeaux, France.

[10] Svab M., Raschman R.: Method for Processing of Soil Leachate Containing PCBs and Anionic Surfactant, patent nr. 294812, 21.1.2005, Czech Republic. 